\title{
Germanica
}

GERMANICA $7 \mid 1990$

Grenze und Entgrenzung

\section{Die «schlechten Wörter» des Hans Joachim Schädlich}

Carine Kleiber

\section{(2) OpenEdition}

1 Journals

Édition électronique

URL : https://journals.openedition.org/germanica/2505

DOI : 10.4000/germanica.2505

ISSN : 2107-0784

Éditeur

Université de Lille

\section{Édition imprimée}

Date de publication : 30 juin 1990

Pagination : 135-139

ISSN : 0984-2632

\section{Référence électronique}

Carine Kleiber, „Die «schlechten Wörter» des Hans Joachim Schädlich“, Germanica [Online], 7 | 1990,

Online erschienen am: 18 Juli 2014, abgerufen am 21 September 2021. URL: http://

journals.openedition.org/germanica/2505 ; DOI: https://doi.org/10.4000/germanica.2505

Ce document a été généré automatiquement le 21 septembre 2021.

(c) Tous droits réservés 


\title{
Die «schlechten Wörter» des Hans Joachim Schädlich
}

\author{
Carine Kleiber
}

1 Ilse Aichingers aus sprachlich-philosophischen Gründen gewählte uneigentliche Form des Sagens, zu der sie sich in Schlechte Wörter bekennt - ich zitiere: Ich gebrauche jetzt die besseren Wörter nicht mehr.

Der Regen, der gegen die Fenster stürzt. Früher wäre mir da etwas ganz anderes eingefallen. Damit ist es jetzt genug... Ich hatte übrigens gerade noch einen anderen Ausdruck auf der Zunge, er war nicht nur besser, er war genauer... ${ }^{1}$

2 - eine solche uneigentliche Form des Sagens hat sich auch Hans Joachim Schädlich zueigen gemacht. So heißt es in Nachlaß²:

Allzu vertraut war ihm (dem Dichter) der kurze Maßstab. Nicht mochte er teilen in Für und Wider und nicht sich bedienen der Worte des anderen: brauchbar und unnütz, und wieder, aber strenger noch, weil abgeschreckt von den Eilfertigen, verwarf er die hastigen Sätze, geschrieben zu schnellem Nutzen.

3 Seine Kurzepik, auf die ich mich hier beschränkt habe, weil sie die literarische Form ist, auf die er, sowohl im Osten als im Westen ansässig, zurückgriff, und die fast ausschließlich an persönliche Ereignisse anknüpft, weist in vielen Fällen einen ähnliche Sprachgestus auf, wenn auch aus anderen Motivationen heraus und mit anderen Kunstgriffen.

4 Abneigung für das Pathetische, Wissen um den allgemeingültigen Charakter der dargestellten menschlichen Unzulänglichkeiten, vorsichtiger Umgang mit brisanten Themen und Wörtern imRahmen seiner Kritik an den politischen und gesellschaftlichen Verhältnissen, Behauptung des autonomen Denkens und Waltens mögen seine wichtigsten Gründe für die Verdichtung, die ungewöhnliche «versuchte Nähe» sein. 


\section{Wie läßt sich das im Einzelnen bewerkstelligen?}

5 1) Durch Umchreibungen, d.h. durch das Zurückgreifen auf Sprachbilder. Indem die verdeckten, traumatischen Tatbestände sich dabei für jeden in etwa mit den Verhältnissen in der DDR vertrauten Leser doch mühelos herauslesen lassen, stellt Schädlich ein Einvernehmen zwischen ihm und dem Leser her, das so etwas wie eine Verbrüderung gegen den gemeinsamen Feind bedeutet.

2) Durch Sprachspiele, die über die Irritation das kritische Denken fördern:

Inz abgelegener Provinz: Daß er aber hören will,was er nicht hören will ${ }^{3}$.

Einzelheit: Daß also das Automobil ohne genügendes Licht nicht fahren kann, wohin es fahren soll bis zum Ende des Tages, daß es aber, wohin es fahren soll, fahren muß bis zum Ende des Tages ${ }^{4}$.

7 3) Durch eine bis zur Absurdität getriebene Akribie bei der Niederschrift von auf den ersten Blick hin völlig banalen Tatbeständen, wobei Mühseligkeit unbeirrbarer Bürokratie nicht benannt oder beschrieben, sondern heraufbeschworen wird:

Papier und Bleistift: Es ist jetzt Zeit, etwas über die tägliche Arbeit zu schreiben: Jeder Chef bekommt einen Chef Vertreter. Dann ist auch der fünfte Chef übergeordnet und untergeordnet. Ferner: Für die Chef Vertreter brauche ich fünf Zimmer. Die Zimmer der Chef Vertreter liegen vor den Zimmern der Chefs, Die Chefvertreter sind jung und durchdrungen. Vor den Zimmern der Chefvertreter richte ich fünf Sekretariate ein. Die Sekretärinnen machen sich hübsch und sprechen mit den Chefvertretern über die Terminkalender. Die Sekretärinnen machen sich schön und lassen sich von Chefs den Text diktieren. Die Sekretärinnen gießen Zimmerpflanzen, rauchen Zigaretten, trinken Kaffee oder Tee, sprechen mit Sekretärinnen, trinken mit Sekretärinnen Tee oder Kaffee, rauchen mit Sekretärinnen Zigarette und gießen Zimmerpflanzen ${ }^{5}$.

8 4) Durch Wiedergabe oft in der Form einer indirekten Rede von Kanzleideutsch zwecks Zersetzung des langläufigen Jargons und von in allen Gebieten des Lebens eingezogenem Kanzleidenken.

Kleine Schule der Poesie: Und was überhaupt Wahrheit heiße? Er meine Wahrheit, die nur seine sei, nicht die anderer. Keiner wolle seine hören, die zu klein sei vor einer größeren ${ }^{6}$.

Halber Tag: Das Koferradio redet den Bericht eines Senders jenseits der Grenze über einen Jahrestag. Der Schutz der Früchte der Arbeit des Volkes ${ }^{7}$.

Einzelheit: das die beiden älteren als Frau und Mann erklärt, die jüngeren aber als Tochter und Tochter des Mannes und der Frau

5) Durch eine bis zum Paradoxon getrieben lakonischdialektische Schreibweise:

Einzelheit: Die Reisenden und die Minderjährigen, wach von der Müdigkeit ${ }^{9}$.

6) Durch eine Collagetechnik, die sich als eine Spurensicherung des Bestürzenden entpuppt. Die einschlägigsten Beispiele liefern die Erzählungen Einseitige Ansehung, Oktoberhimmel, Ostwestberlin ${ }^{10}$.

11 7) Durch Verschlüsselung an Hand von Parabeln, jener literarischen Form, die für die Freiheit des Wortes mißachtenden Gesellschaften typisch ist.

Und diese Palette von Stilmitteln weist im Hinblick auf den Begriff der Entgrenzung zwei entgegengesetzte Tendenzen auf: Bezeichnen wir die erste in Anlehnung an Handke als die Darstellung der Außenwelt der Innenwelt. Hier greift Schädlich vor allem auf fingierte historische Bilder und Szenen zurück, die durch ständige literarische Bezüge Dialoge und Monologe in vorzüglichster klassisch-romantischer 
Manier, durch Bilder von kaum erträglicher Vornehmheit, eine Autentizität erhalten, mit der sich jedoch kaum etwas anfangen läßt ohne eine Bezugsherstellung zur Gegenwart. «Es ist nichts Beobachter sein. Der Beobachter sieht nichts», heißt es in Johannes Bobrowskis Erzählung Rainfarn ${ }^{11}$. So erwartet Schädlich z.B. von den Lesern, daß sie die Glanzzeiten Preußens in den Alltag der DDR übersetzen, so daß das Hierarchiedenken und dessen verheerende Auswirkungen nicht mehr als historisch bedingt an eine gesellschaftliche Form gebunden erscheint. So brauchen die Wortführer der DDR nicht beim Titel genannt zu werden. Zeitentrückte Bezeichnungen wie Kaiser oder Herrscher wirken weniger verfänglich; wenn auch der Unterton umso mißbilligender ist.

Neben der Technik der Radiographie, die das eigentliche hinter dem Uneigentlichen verbirgt, bedient sich Schädlich jener der Photographie: Wir kommen zur Darstellung der Außenwelt der Innenwelt, d.h. zu einem durch parataktische Fügung Fixieren sinnlicher Eindrücke, einem Aufzählen von Details, die ähnlich wie die Bäume, vor denen man keinen Wald mehr sieht, mit allen Mitteln den wunden Punkt, um den es geht, verdecken, verschweigen, allerdings immer nur so viel, daß der Kunstgriff nicht zum Fehlgriff entartet. So umschleicht in Oktoberhimmel ein gewisser Herr H die Gegend um das Brandenburger Tor folgendermaßen:

Das Bauwerk am Ende des Platzes, das in Sandstein aufgeführt ist, hat zwölf gewaltige Säulen, sechs der Stadtseite, sechs der Waldseite zugekehrt, so daß ein Betrachter, bemerkt Herr H., der, wie er, einigermaßen entfernt gerade in der Mitte vvor dem Bauwerk sich befindet, bloß sechs wahrnimmt. Die Säulen, die fünf Durchfahrten bilden, sind durch Zwischenwände miteinander verbunden. Auf den Wänden sind flachgewölbte Bildwerke sichtbar [...]. Beidseits des Bauwerks hat man Säulenhallen gebaut, die zu dienstlichen Lokalen bestimmt sind; die linke für die Wache. Zwischen der letzten Querstraße und dem Gländer, Drehkreuz, Geländer, Schlagbaum, Geländer, Gemäuer, Geländer stehen Zuschauer oder gehen umher ${ }^{12}$. erfinderisch, und gewiß, die auf allen Gebieten des alltäglichen Lebens erfahrene Begrenzung hat Schädlich zu seinen besten Texten angeregt.

\section{NOTES}

1. - S. Fischer Verlag, Frankfurt M 1976, S. 7.

2. - In «Versuchte Nähe», Rowohlt Taschenbuch, Reinbek bei Hamburg, 1980, S. 73.

3. - In «Ostwestberlin», Rowohlt Verlag, Reinbek bei Hamburg, 1987, S. 7.

4. - In «Ostwestberlin», S. 15.

5. - In «Versuchte Nähe», S. 163-164.

6. - In «Versuchte Nähe», S. 28.

7. - In «Ostwestberlin», S. 40.

8. - In «Ostwestberlin», S. 13.

9. - In «Ostwestberlin», S. 16.

10. - «Einseitige Ansehung» und «Oktoberhimmel» in «Versuchte Nähe» und « Ost westberlin » im gleichnamigen Band. 
11. - In «Boehlendorff und Mäusefest», Union Verlag, Berlin 19673, S, 115.

12. - S. 151.

\section{AUTEUR}

\section{CARINE KLEIBER}

Université de Haute Alsace 